\title{
A Stability-Indicating HPLC-DAD Method for Determination of Ferulic Acid into Microparticles: Development, Validation, Forced Degradation, and Encapsulation Efficiency
}

\author{
Jessica Mendes Nadal, ${ }^{1}$ Maria da Graça Toledo, ${ }^{1}$ Yasmine Mendes Pupo, ${ }^{2}$ \\ Josiane Padilha de Paula, ${ }^{3}$ Paulo Vitor Farago, ${ }^{3}$ and Sandra Maria Warumby Zanin ${ }^{1}$ \\ ${ }^{1}$ Postgraduate Program in Pharmaceutical Sciences, Department of Pharmacy, Federal University of Paraná, \\ 632 Lothário Meissner Avenue, 80210-170 Curitiba, PR, Brazil \\ ${ }^{2}$ Postgraduate Program in Dentistry, Department of Dentistry, State University of Ponta Grossa, 4748 Carlos Cavalcanti Avenue, \\ 84030-900 Ponta Grossa, PR, Brazil \\ ${ }^{3}$ Postgraduate Program in Pharmaceutical Sciences, Department of Pharmaceutical Sciences, State University of Ponta Grossa, \\ 4748 Carlos Cavalcanti Avenue, 84030-900 Ponta Grossa, PR, Brazil
}

Correspondence should be addressed to Paulo Vitor Farago; pvfarago@gmail.com

Received 12 January 2015; Revised 24 April 2015; Accepted 25 April 2015

Academic Editor: Sibel A. Ozkan

Copyright ( 2015 Jessica Mendes Nadal et al. This is an open access article distributed under the Creative Commons Attribution License, which permits unrestricted use, distribution, and reproduction in any medium, provided the original work is properly cited.

\begin{abstract}
A simple stability-indicating HPLC-DAD method was validated for the determination of ferulic acid (FA) in polymeric microparticles. Chromatographic conditions consisted of a RP $\mathrm{C}_{18}$ column $(250 \mathrm{~mm} \times 4.60 \mathrm{~mm}, 5 \mu \mathrm{m}, 110 \AA)$ using a mixture of methanol and water $\mathrm{pH} 3.0(48: 52 \mathrm{v} / \mathrm{v})$ as mobile phase at a flow rate of $1.0 \mathrm{~mL} / \mathrm{min}$ with UV detection at $320 \mathrm{~nm}$. The developed method was validated as per ICH guidelines with respect to specificity, linearity, limit of quantification, limit of detection, accuracy, precision, and robustness provided suitable results regarding all parameters investigated. The calibration curve was linear in the concentration range of $10.0-70.0 \mu \mathrm{g} / \mathrm{mL}$ with a correlation coefficient $>0.999$. Precision (intraday and interday) was demonstrated by a relative standard deviation lower than $2.0 \%$. Accuracy was assessed by the recovery test of FA from polymeric microparticles (99.02\% to $100.73 \%)$. Specificity showed no interference from the components of polymeric microparticles or from the degradation products derived from acidic, basic, and photolytic conditions. In conclusion, the method is suitable to be applied to assay FA as bulk drug and into polymeric microparticles and can be used for studying its stability and degradation kinetics.
\end{abstract}

\section{Introduction}

Ferulic acid (FA; $\mathrm{C}_{10} \mathrm{H}_{10} \mathrm{O}_{4}$; MW: $\left.194.18 \mathrm{Da}\right)$ or $(E)-3-(4-$ hydroxy-3-methoxy-phenyl)prop-2-enoic acid (Figure 1) is a chemical compound widely found in vegetables which has a low degree of toxicity after oral administration [1]. In nature, it is biosynthesized from phenylalanine and $\mathrm{L}^{-}$ tyrosine by shikimate pathway and occurs mainly as trans isomer $[2,3]$. FA is characterized as an off-white to light yellowish brown crystalline powder that has aqueous solubility of $6.63 \mathrm{mg} / \mathrm{dL}$ at $\mathrm{pH} 7.2$ [4], pKa of 4.58, melting range between 168 and $171^{\circ} \mathrm{C}$, half-life of $42 \mathrm{~min}$ [5], and $\log P$ of 1.67 [6]. In particular, FA has been proposed as a novel antioxidant drug endowed with a strong cytoprotective activity due to both the ability to scavenge free radicals and activate cell stress response [1]. Previous studies have demonstrated that it has diverse therapeutic activity, including anti-inflammatory, antioxidant, antithrombotic, anticancer, cardioprotective, and neuroprotective effects. When used on the skin, FA shows a photoprotective effect $[2,7-11]$.

In spite of the remarkable pharmacological potential, FA has a poor solubility in aqueous medium [7] and presents an unfavorable pharmacokinetics which reduces its bioavailability and clinical efficacy after oral administration [12]. In order to increase FA bioavailability and enhance its cytoprotective effects, new formulations have been prepared in which this 


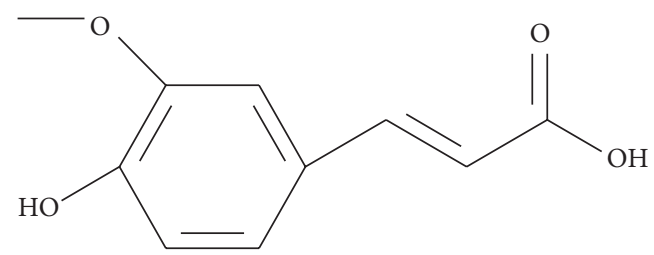

FIgURE 1: Chemical structure of ferulic acid (FA).

phenolic acid is entrapped either in solid lipid nanoparticles or in niosomes or is bound to other therapeutic agents through organic moieties (e.g., amino acids) which serve as carriers [1]. However, no paper was devoted to investigate the use of polymeric microparticles as a pharmaceutical approach for improving the therapeutic efficacy of FA by prolonging its retention time into the gastrointestinal tract.

Polymeric microparticles are widely studied carriers for the controlled release application of drugs. These multipleunit pharmaceutical dosage forms are solid and show spherically shaped particles ranging in size from 1 to $1000 \mu \mathrm{m}$, in which the drug can be either adsorbed at the surface of the polymer or encapsulated within the polymer [13]. The advantages of using such carriers include potential to increase the bioavailability of poorly water-soluble drugs, ability to control the rate and/or the site of drug release, possibility to improve drug stability related to enzymatic, environmental, or chemi$\mathrm{cal} /$ photochemical degradation, elimination of incompatibilities among different drugs, and as a taste-masking approach $[14,15]$. Various methods are readily available for microencapsulation of drugs and one of the most commonly used is emulsion/solvent evaporation [16]. This procedure can be performed via various protocols and the selection for best option depends on the property of the compounds that are intended to be encapsulated [17]. In our laboratory, experiments are being carried out in order to formulate FA-loaded polymeric microparticles using the simple emulsion/solvent evaporation technique and two biocompatible and biodegradable polyesters, poly( $\varepsilon$-caprolactone) (PCL) and poly(3-hidroxybutirate-co-3-hidroxyvalerate) (PHBV). However, an analytical validation procedure is required for assaying FA from these formulations at the same time.

The literature reports few HPLC methods for determining FA from different sample types as summarized in Table 1. These papers are mainly devoted to describing HPLC methods for isolation and analytical and bioanalytical quantification of FA from medicinal herbs and foods. Only two papers used HPLC method for quantifying FA from inclusion complexes that were prepared using cyclodextrins $[2,18]$. However, none of these two studies involving cyclodextrins were submitted to the required validation process. In that sense, no work was found on validation of analytical methods for determining FA as bulk drug and from pharmaceutical formulations.

According to The International Conference on Harmonization (ICH) stability guideline [19], stress testing of a drug substance can be carried out to elucidate its inherent stability characteristics under hydrolytic, oxidative, and photolytic conditions. Considering FA, to the best of our knowledge, there is no stability-indicating method previously published for this drug.

Taking all the above into account, in the current paper, a fast, simple, and optimized reverse-phase HPLC method with UV detection was developed and validated for quantifying FA in polymeric microparticles. Other experiments were also performed to explore forced degradation of the drug under stress conditions as per the ICH guidelines [19-21].

\section{Materials and Methods}

2.1. Reagents and Chemicals. Ferulic acid 99.80\% (FA, Suzhou Leader Chemical Co. Ltda., Suzhou, China), poly( $\varepsilon$ caprolactone) (PCL) $\left(\overline{M_{w}}=70000-90000 \mathrm{~g} / \mathrm{mol}\right.$, SigmaAldrich, St. Louis, MO, USA), poly(3-hidroxybutirate-co-3hidroxyvalerate) (PHBV) $\left(\overline{M_{w}}=380000 \mathrm{~g} / \mathrm{mol}, 8.70 \mathrm{~mol} \%\right.$ hydroxyvalerate, Biocycle L110, PHB Industrial, Serrana, Brazil), and poly(vinyl alcohol) (PVA) $\left(\overline{M_{w}}=72000 \mathrm{~g} / \mathrm{mol}\right.$, $88.5 \mathrm{~mol} \%$ of hydrolysis, Vetec, Rio de Janeiro, Brazil) were used as received. As an internal standard, trans-ferulic acid, matrix substance $\geq 99.0 \%$ (HPLC), was purchased from Sigma-Aldrich (St. Louis, MO, USA). HPLC-grade methanol was also provided by Sigma-Aldrich (St. Louis, MO, USA). Water was purified in a Milli-Q Plus water purification system (Millipore, Bedford, MA, USA). All other reagents and solvents were of analytical grade.

2.2. Equipment. A Varian Pro-star SYS-LC-240-E HPLC system (Walnut Creek, CA, USA) was used for method development. The HPLC system was equipped with a column oven compartment (model ProStar 410), an on-line degasser (model ProStar 230), a ternary pump (model ProStar 230), a solvent delivery module (model ProStar 230), an auto sampler (model ProStar 410), and a photodiode array detector (DAD) (model ProStar 335). Data acquisition, analysis, and reporting were performed using Varian Star Workstation chromatography software (Walnut Creek, CA, USA).

2.3. Chromatographic Conditions. Experiments were performed in the previously described HPLC system using a Varian $\mathrm{C}_{18}$ analytical column (Walnut Creek, CA, USA) with $5 \mu \mathrm{m}$ particle size, $4.6 \mathrm{~mm}$ internal diameter, and $250 \mathrm{~mm}$ length at $25 \pm 2^{\circ} \mathrm{C}$. The mobile phase consisted of methanol and water adjusted to $\mathrm{pH} 3.0$ with orthophosphoric acid $0.1 \mathrm{~N}$ $(48: 52 \mathrm{v} / \mathrm{v})$ at an isocratic flow rate of $1.0 \mathrm{~mL} / \mathrm{min}$. The sample injection volume was $10 \mu \mathrm{L}$. FA was monitored at $320 \mathrm{~nm}$. The method run time was 8 minutes and all experiments were carried out in triplicate.

2.4. Preparation of Polymeric Microparticles. The polyester microparticles containing FA were prepared by simple emulsion/solvent evaporation [22]. Three different formulations (Table 2) were obtained for each polymer (PHBV/PCL) depending on the amount of FA into their compositions (5, 10 , and $20 \%$ ). Chloroform and methylene chloride were used as polymer solvent for PHBV and PCL, respectively. Briefly, the organic phase was added into the aqueous phase under mechanical stirring $(5000 \mathrm{rev} / \mathrm{min})$ for $5 \mathrm{~min}$. The emulsion 
TABLE 1: Previous papers that report HPLC methods for isolation and quantification of FA.

\begin{tabular}{|c|c|c|c|}
\hline Sample type & Chromatographic conditions & $\begin{array}{l}\text { Was the } \\
\text { (bio)analytical } \\
\text { validation process } \\
\text { carried out? }\end{array}$ & Reference \\
\hline $\begin{array}{l}\text { Rat plasma after oral } \\
\text { administration of Chuanxiong } \\
\text { rhizome and its related } \\
\text { preparation (Suanzaoren) }\end{array}$ & $\begin{array}{l}\text { Column: Hypersil } \mathrm{C}_{18} \text { column }(200 \times 4.6 \mathrm{~mm}, 5 \mu \mathrm{m}) \text {; } \\
\text { mobile phase: acetonitrile : water }(16: 84 \mathrm{v} / \mathrm{v}) \text { containing } \\
1 \% \text { glacial acetic acid; injection volume: } 20 \mu \mathrm{L} \text {; flow rate: } \\
0.8 \mathrm{~mL} / \mathrm{min} \text {; column temperature: ambient; detection: } \\
\text { UV }(320 \mathrm{~nm}) \text {; retention time: } 12.7 \mathrm{~min} .\end{array}$ & Yes & {$[23]$} \\
\hline $\begin{array}{l}\text { Ferulic acid } / \gamma \text {-cyclodextrin } \\
\text { inclusion complex }\end{array}$ & $\begin{array}{l}\text { Column: Supelcosil LC- } 18(250 \times 4.6 \mathrm{~mm}, 5 \mu \mathrm{m}) \text {; } \\
\text { mobile phase: acetonitrile : water }(2 \% \text { acetic acid }) \\
(22: 78 \mathrm{v} / \mathrm{v}) \text {; injection volume: } 20 \mu \mathrm{L} \text {; flow rate: } \\
1.0 \mathrm{~mL} / \mathrm{min} \text {; column temperature: ambient; detection: } \\
\text { UV }(320 \mathrm{~nm}) \text {; retention time: } 10.5 \mathrm{~min} .\end{array}$ & No & {$[18]$} \\
\hline $\begin{array}{l}\text { Rabbit plasma after intravenous } \\
\text { administration of danxiongfang } \\
\text { (a Chinese medicine formula } \\
\text { used to treat atherosclerosis and } \\
\text { vascular restenosis) }\end{array}$ & $\begin{array}{l}\text { Column: Agilent } \mathrm{HC}-\mathrm{C}_{18}(250 \times 4.6 \mathrm{~mm}, 5 \mu \mathrm{m}) \text {; mobile } \\
\text { phase: methanol : water }(0.5 \% \text { glacial acetic acid }) \\
(20: 80 \text { to } 80: 20 \mathrm{v} / \mathrm{v}) \text {; injection volume: } 20 \mu \mathrm{L} \text {; flow } \\
\text { rate: } 1.0 \mathrm{~mL} / \mathrm{min} \text {; column temperature: ambient; } \\
\text { detection: } \mathrm{UV}(281 \mathrm{~nm}) \text {; retention time: } 7.78 \mathrm{~min} \text {. }\end{array}$ & Yes & {$[24]$} \\
\hline $\begin{array}{l}\text { Ma-Zu-Wan-Show-Yao-Jyo (a } \\
\text { Chinese tonic wine) }\end{array}$ & $\begin{array}{l}\text { Column: Cosmosil } 5 \mathrm{C}_{18} \text {-AR-II }(250 \times 4.6 \mathrm{~mm}, 5 \mu \mathrm{m}) \text {; } \\
\text { mobile phase: water adjusted to } \mathrm{pH} 3.0 \text { with } 0.1 \mathrm{~N} \\
\text { phosphoric acid : acetonitrile }(65: 35 \text { to } 75: 25 \mathrm{v} / \mathrm{v}) \text {; } \\
\text { injection volume: } 20 \mu \mathrm{L} \text {; flow rate: } 1.0 \mathrm{~mL} / \mathrm{min} \text {; column } \\
\text { temperature: ambient; detection: } \mathrm{UV}(285 \mathrm{~nm}) \text {; } \\
\text { retention time: } 10.0 \mathrm{~min} \text {. }\end{array}$ & Yes & {$[25]$} \\
\hline $\begin{array}{l}\text { Xuebijing injection (a } \\
\text { traditional Chinese medicine } \\
\text { for treating sepsis) }\end{array}$ & $\begin{array}{l}\text { Column: Zorbox } \mathrm{SB}_{18}(250 \times 4.6 \mathrm{~mm}, 5 \mu \mathrm{m}) \text {; mobile } \\
\text { phase: } 0.2 \% \text { phosphoric acid : acetonitrile in gradient } \\
\text { elution; injection volume: } 20 \mu \mathrm{L} \text {; flow rate: } 1.0 \mathrm{~mL} / \mathrm{min} \text {; } \\
\text { column temperature: ambient. }\end{array}$ & Yes & {$[26]$} \\
\hline Rice (Oryza sativa L.) & $\begin{array}{l}\text { Column: } \mathrm{C}_{18} \text { Waters Symmetry column }(150 \times 3.9 \mathrm{~mm} \text {, } \\
5 \mu \mathrm{m}) \text { coupled to a guard column; mobile phase: } 1 \% \\
(\mathrm{v} / \mathrm{v}) \text { acetic acid : acetonitrile in gradient elution; } \\
\text { injection volume: } 20 \mu \mathrm{L} \text {; flow rate: } 0.8 \mathrm{~mL} / \mathrm{min} \text {; column } \\
\text { temperature: } 30^{\circ} \mathrm{C} \text {; detection: } \mathrm{UV}(280 \mathrm{~nm}) \text {; retention } \\
\text { time: } 18 \mathrm{~min} \text {. }\end{array}$ & Yes & {$[27]$} \\
\hline $\begin{array}{l}\text { Ferulic acid/hydroxypropyl- } \beta \text { - } \\
\text { cyclodextrin inclusion } \\
\text { complex }\end{array}$ & $\begin{array}{l}\text { Column: } \mathrm{C}_{18} \text { Symmetry column }(150 \times 3.9 \mathrm{~mm} ; 5 \mu \mathrm{m}) \text {; } \\
\text { mobile phase: methanol : water : acetic acid } \\
(50: 50: 0.5) \text {; injection volume: } 10 \mu \mathrm{L} \text {; flow rate: } \\
0.8 \mathrm{~mL} / \mathrm{min} \text {; column temperature: } 30^{\circ} \mathrm{C} \text {; detection: } \mathrm{UV} \\
(313 \mathrm{~nm}) \text {; retention time: } 15 \mathrm{~min} .\end{array}$ & No & {$[2]$} \\
\hline $\begin{array}{l}\text { Insampaedok-san } \\
\text { (a traditional oriental medicine } \\
\text { prescription for treating } \\
\text { cold-related symptoms) }\end{array}$ & $\begin{array}{l}\text { Column: Shiseido } \mathrm{C}_{18} \text { column }(250 \times 4.6 \mathrm{~mm}, 5 \mu \mathrm{m}) \text {; } \\
\text { mobile phase: water with } 0.1 \% \text { trifluoroacetic acid: } \\
\text { methanol in gradient elution; injection volume: } 20 \mu \mathrm{L} \text {; } \\
\text { flow rate: } 1.0 \mathrm{~mL} / \mathrm{min} \text {; column temperature: } 35^{\circ} \mathrm{C} \text {; } \\
\text { detection: } \mathrm{UV}(320 \mathrm{~nm}) \text {; retention time: } 22.07 \mathrm{~min} \text {. }\end{array}$ & Yes & {$[28]$} \\
\hline $\begin{array}{l}\text { Nao-De-Sheng } \\
\text { (a tradicional Chinese formula } \\
\text { containing Chuanxiong } \\
\text { rhizome) }\end{array}$ & $\begin{array}{l}\text { Column: } \mathrm{C}_{18} \text { column }(250 \times 4.6 \mathrm{~mm}, 5 \mu \mathrm{m}) \text {; mobile } \\
\text { phase: methanol : water }(0.5 \% \text { acetic acid })(30: 70 \mathrm{v} / \mathrm{v}) \text {; } \\
\text { injection volume: } 20 \mu \mathrm{L} \text {; flow rate: } 1.0 \mathrm{~mL} / \mathrm{min} \text {; column } \\
\text { temperature: } 35^{\circ} \mathrm{C} \text {; detection: } \mathrm{UV}(320 \mathrm{~nm}) \text {; retention } \\
\text { time: } 15.02 \mathrm{~min} \text {. }\end{array}$ & Yes & {$[29]$} \\
\hline $\begin{array}{l}\text { Ferula asafoetida and a } \\
\text { polyherbal preparation }\end{array}$ & $\begin{array}{l}\text { Column: HiQSil ODS C- } 18(250 \times 4.6 \mathrm{~mm}, 5 \mu \mathrm{m}) \text {; } \\
\text { mobile phase: acetonitrile: } 10 \% \text { acetic acid }(20: 80 \mathrm{v} / \mathrm{v}) \text {, } \\
\text { pH } 2.25 \text {; injection volume: } 20 \mu \mathrm{L} \text {; flow rate: } 1.0 \mathrm{~mL} / \mathrm{min} \text {; } \\
\text { column temperature: } 30^{\circ} \mathrm{C} \text {; detection: } \mathrm{UV}(319 \mathrm{~nm}) \text {; } \\
\text { retention time: } 10.24 \text { min. }\end{array}$ & Yes & {$[30]$} \\
\hline
\end{tabular}


TABLE 2: Composition of ferulic acid-loaded and unloaded PHBV/PCL microparticles.

\begin{tabular}{|c|c|c|c|c|c|c|c|c|}
\hline \multirow{2}{*}{ Composition } & \multicolumn{8}{|c|}{ Formulation } \\
\hline & M1FA0 & M1FA5 & M1FA10 & M1FA20 & M2FA0 & M2FA5 & M2FA10 & M2FA20 \\
\hline \multicolumn{9}{|l|}{ Aqueous phase } \\
\hline Polysorbate 80 (g) & 0.25 & 0.25 & 0.25 & 0.25 & 0.25 & 0.25 & 0.25 & 0.25 \\
\hline PVA (g) & 4.00 & 4.00 & 4.00 & 4.00 & 4.00 & 4.00 & 4.00 & 4.00 \\
\hline Purified water $(\mathrm{mL})$ & 200.0 & 200.0 & 200.0 & 200.0 & 200.0 & 200.0 & 200.0 & 200.0 \\
\hline \multicolumn{9}{|l|}{ Organic phase } \\
\hline Ferulic acid (g) & - & 0.10 & 0.20 & 0.40 & - & 0.10 & 0.20 & 0.40 \\
\hline PHBV (system M1) (g) & 2.00 & 1.90 & 1.80 & 1.60 & - & - & - & - \\
\hline PCL (system M2) (g) & - & - & - & - & 2.00 & 1.90 & 1.80 & 1.60 \\
\hline Chloroform (mL) & 40.0 & 40.0 & 40.0 & 40.0 & - & - & - & - \\
\hline Methylene chloride (mL) & - & - & - & - & 40.0 & 40.0 & 40.0 & 40.0 \\
\hline
\end{tabular}

was kept under mechanical stirring $(800 \mathrm{rev} / \mathrm{min})$ at room temperature $\left(25 \pm 2^{\circ} \mathrm{C}\right)$ for $4 \mathrm{~h}$. After organic solvent evaporation, microparticles were separated by centrifugation (2500 rev/min, $10 \mathrm{~min}$ ), washed twice with purified water, and dried under vacuum at $35 \pm 2^{\circ} \mathrm{C}$ for $4 \mathrm{~h}$. The samples were stored into a desiccator under vacuum at room temperature $\left(25 \pm 2^{\circ} \mathrm{C}\right)$. All formulations were obtained in triplicate. Unloaded-microparticles were also prepared as negative controls (M1FA0 and M2FA0). All procedures were performed in dark conditions.

2.5. Preparation of Standard Solutions. A stock standard solution $(1 \mathrm{mg} / \mathrm{mL})$ was daily prepared by dissolving $50 \mathrm{mg}$ of FA into a $50 \mathrm{~mL}$ volumetric flask using methanol. This solution was further diluted in methanol to prepare seven different working standard solutions ranging from 10.0 to $70.0 \mu \mathrm{g} / \mathrm{mL}$. These solutions were filtered through a poly(vinylidene fluoride) membrane filter (Durapore membrane, $0.45 \mu \mathrm{m}$ pore size, Millipore, Bedford, MA, USA) before injection into the HPLC system. All procedures were carried out in dark conditions.

2.6. Preparation of Sample Solutions. For FA quantification, the amount of drug into FA-loaded PHBV/PCL microparticles was indirectly determined. As previously described, microparticles were centrifuged at $2500 \mathrm{rev} / \mathrm{min}$ for $10 \mathrm{~min}$ utes and washed twice with purified water after organic solvent evaporation. Free FA was assayed in the supernatant after its suitable dilution and filtration through a $0.45 \mu \mathrm{m}$ poly(vinylidene fluoride) membrane filter by injection into the HPLC system.

2.7. Method Development. Detection wavelength for the HPLC study was selected as $320 \mathrm{~nm}$. The chromatographic conditions were optimized for resolution of the peak of FA by varying the composition and proportion of the mobile phase. Samples of different formulations were used to optimize the chromatographic conditions for resolving FA. An appropriate blank was injected before the analysis of all samples. The method was then validated and used for the determination of FA into PHBV/PCL microparticles.
2.8. Method Validation. Validation studies were performed using the optimized chromatographic conditions based on the principles of validation described in the International Conference Harmonization (ICH) guidelines [21]. The method was validated for specificity, linearity, limit of detection (LOD), limit of quantitation (LOQ), accuracy, precision, and robustness.

The specificity was determined by analyzing the chromatograms of unloaded microparticles (M1FA0 and M2FA0) in comparison with those obtained for FA-loaded microparticles (M1FA10 and M2FA10) aiming at confirming that none of the excipients interfere with the quantitation of the drug.

The linearity was determined by calculating a regression line from the plot of the peak area versus concentration of the working standard solutions prepared at seven concentration levels $(10.0,20.0,30.0,40.0,50.0,60.0$, and $70.0 \mu \mathrm{g} / \mathrm{mL})$ using least-squares linear regression analysis. The linearity test was performed for 3 consecutive days in the same concentration range. The solutions were injected in triplicate into the HPLC column keeping the injection volume constant $(10 \mu \mathrm{L})$ and chromatograms were recorded. The standard deviation (SD) value for the slope and $Y$-intercept of the calibration curve were calculated.

LOD and LOQ were calculated based on the standard deviation of the response $(\delta)$ and the slope $(S)$ of the calibration curve and were expressed as $3.3 \delta / S$ and $10 \delta / S$ for LOD and LOQ, respectively.

The accuracy of the analytical method was investigated by spiking unloaded microparticles (M1FA0 and M2FA0) with known concentrations of the stock solution to achieve final theoretical drug concentrations of 15,45 , and $65 \mu \mathrm{g} / \mathrm{mL}$. The accuracy value was determined by calculating the percent recovery of FA for these three concentration levels and then determining the relative standard deviation (RSD).

The precision was assessed at two levels: repeatability (intraday precision) and intermediate precision (interday precision) using M1FA10. The repeatability was investigated by testing three different sample solutions at 15, 40, and $65 \mu \mathrm{g} / \mathrm{mL}$ on the same day. Three samples solutions at $40 \mu \mathrm{g} / \mathrm{mL}$ were also evaluated in other two different days in order to determine intermediate precision. Results were reported in terms of RSD. 
In order to determine the robustness, experimental conditions were purposely changed to check the reproducibility of the method. Robustness was evaluated by analyzing drug content of the microparticles (M1FA10) with variations in the temperature of analytical column $\left(30\right.$ and $\left.40^{\circ} \mathrm{C}\right)$, flow rate $(0.9$ and $1.1 \mathrm{~mL} / \mathrm{min})$, and $\mathrm{pH}$ of mobile phase $(4.0$ and 6.0). Samples were evaluated in triplicate for each variation of the method conditions. Chromatograms were recorded and compared with the previously reported chromatographic conditions.

2.9. Forced Degradation Study. Forced degradation studies were also carried out in order to provide some information about drug stability and specificity of the proposed method. The standard solution of FA was subject to accelerated degradation by acid, basic, and photolytic conditions.

To investigate the acid degradation, $6.25 \mathrm{~mL}$ of the stock standard solution $(1.0 \mathrm{mg} / \mathrm{mL})$ was diluted into a $25 \mathrm{~mL}$ volumetric flask with $0.1 \mathrm{M} \mathrm{HCl}$. This solution was maintained at room temperature $\left(25 \pm 2^{\circ} \mathrm{C}\right)$ and protected from light for $1 \mathrm{~h}$. After the reaction time, the solution was neutralized using $0.1 \mathrm{M} \mathrm{NaOH}$. The solution was diluted with methanol to achieve a final concentration of $40 \mu \mathrm{g} / \mathrm{mL}$ before injection into the HPLC system. The same procedure was used for the alkaline degradation, except by the fact that $0.1 \mathrm{M} \mathrm{HCl}$ was replaced by $0.1 \mathrm{M} \mathrm{NaOH}$ in sample preparation.

For photodegradation, $3 \mathrm{~mL}$ of FA methanol solution $(1 \mathrm{mg} / \mathrm{mL})$ was placed in a quartz cuvette and subsequently exposed to UV radiation (Phillips TUV lamp-254 nm, $30 \mathrm{~W}$ ) for $6 \mathrm{~h}$ in a mirrored chamber $(1 \mathrm{~m} \times 25 \mathrm{~cm} \times 25 \mathrm{~cm})$ at a fixed distance. At predetermined times $(0,1,2,3,4,5$, and $6 \mathrm{~h}$ ) of exposure to light, $400 \mu \mathrm{L}$ of the samples were withdrawn and diluted with methanol (final concentration of $40 \mu \mathrm{g} / \mathrm{mL}$ of $\mathrm{FA}$ ) in order to quantify the remaining FA according to the method previously described. In order to refute the hypothesis of thermal degradation, a cuvette containing FA methanol solution (final concentration of $40 \mu \mathrm{g} / \mathrm{mL}$ of FA) was covered by aluminum paper and was evaluated as the same way. The degradation rate kinetics of FA was determined and the best fit was used for indicating the reaction order. The kinetic models used were zero order $\left(C=C_{\mathrm{o}}-\mathrm{kt}\right)$, first order $\left(\ln C=\ln C_{\mathrm{o}}-\mathrm{kt}\right)$, and second order equation $\left(1 / C=1 / C_{o}+k t\right)$.

2.10. Evaluation of Encapsulation Efficiency. In order to demonstrate the applicability of the validated method, the encapsulation efficiency (EE) of FA into PHBV/PCL microparticles was calculated using (1) from the HPLC results provided by sample solutions:

$$
\begin{aligned}
\mathrm{EE}(\%)= & \frac{\text { total drug content }- \text { free drug content }}{\text { total drug content }} \\
& \times 100 .
\end{aligned}
$$

\section{Results and Discussion}

3.1. Method Development and Optimization. Previous tests were carried out in order to provide a quick and effective

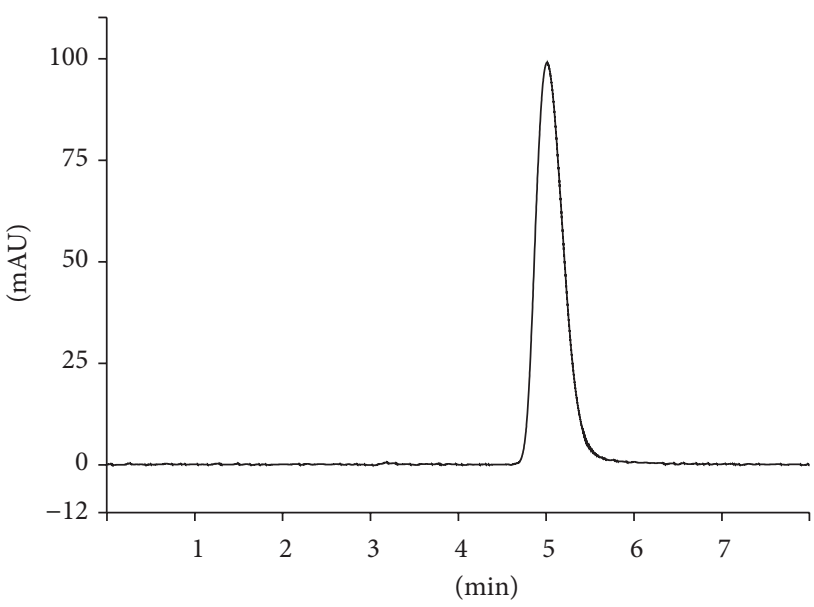

FIGURE 2: Representative HPLC chromatogram of ferulic acid standard $(40 \mu \mathrm{g} / \mathrm{mL})$ in methanol : water adjusted to $\mathrm{pH}$ 3.0. Mobile phase: methanol: water adjusted to $\mathrm{pH} 3.0$ using orthophosphoric acid $(48: 52 \mathrm{v} / \mathrm{v})$; flow rate: $1.0 \mathrm{~mL} / \mathrm{min}$; detection wavelength: $320 \mathrm{~nm}$; column temperature: $25 \pm 2^{\circ} \mathrm{C}$; and injection volume: $10 \mu \mathrm{L}$.

method for analyzing FA using HPLC. The investigated chromatographic conditions were mainly related to the mobile phase composition. Initial runs were performed using a mobile phase mixture of acetonitrile : water $(16: 84 \mathrm{v} / \mathrm{v})$ containing $1 \%$ glacial acetic acid based on a previously reported method for FA quantification in plasma [23]. However, irregular peaks were observed, showing low chromatographic resolution probably due to instrumental and column differences.

In order to improve the quality of chromatographic method, various ratios in isocratic mode were tested using different mixtures of acetonitrile: methanol: water adjusted to $\mathrm{pH} 3.0$ with acetic acid. These assays demonstrated that the proportion of acetonitrile: methanol: water adjusted to pH 3.0 with acetic acid $(24: 24: 52 \mathrm{v} / \mathrm{v})$ was more appropriate for the method optimization. In spite of the symmetry of FA peak, no repeatability and accuracy were observed using this mobile phase.

Therefore, additional experiments were carried out removing acetonitrile and using acetic acid and orthophosphoric acid as acidifying agents at different $\mathrm{pH}$ values. The mobile phase composed by methanol: water adjusted to $\mathrm{pH}$ 3.0 using orthophosphoric acid $(48: 52 \mathrm{v} / \mathrm{v})$ provided a lower tailing and a more symmetric peak for FA with a lower retention time (theoretical plates $=1253, k^{\prime}=3.77$, and tail factor $=1.3$ ). The peak was detected at $4.86 \mathrm{~min}$ (Figure 2) which is very suitable for routine analyses.

In summary, methanol: water adjusted to $\mathrm{pH} 3.0$ using orthophosphoric acid $(48: 52 \mathrm{v} / \mathrm{v})$, column temperature at $25 \pm 2^{\circ} \mathrm{C}$, sample injection volume of $10 \mu \mathrm{L}$, isocratic flow rate of $1.0 \mathrm{~mL} / \mathrm{min}$, detector set at $320 \mathrm{~nm}$, and run time of 8 minutes were chosen as suitable chromatographic conditions for further procedures including the method validation.

3.2. Method Validation. The proposed method was validated by determining its performance characteristics regarding 


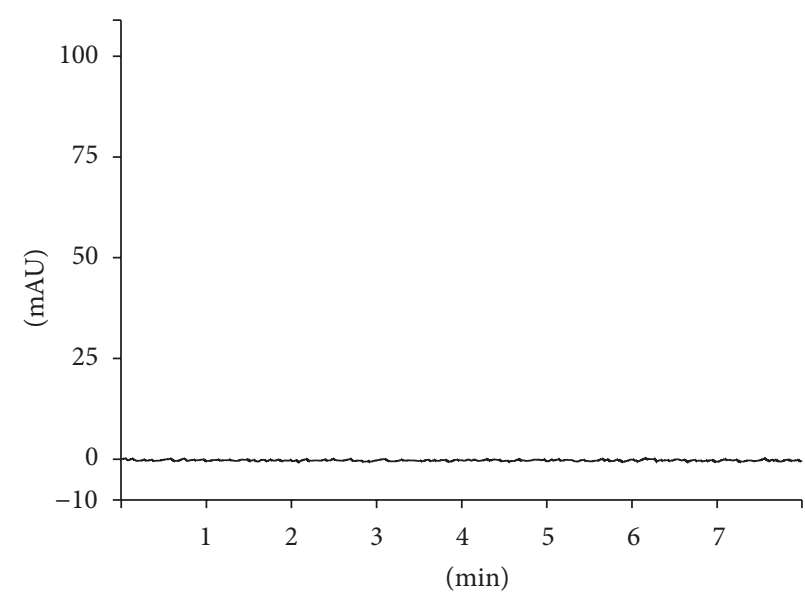

(a)

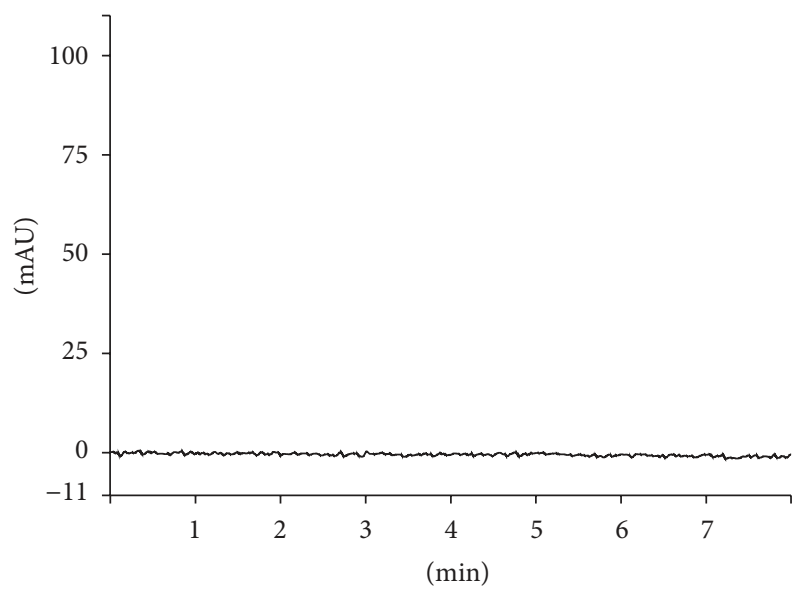

(c)

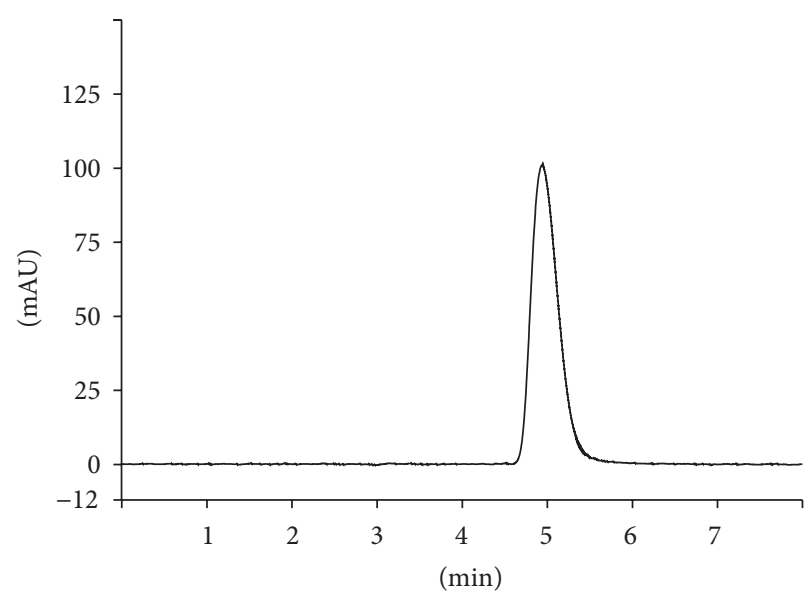

(b)

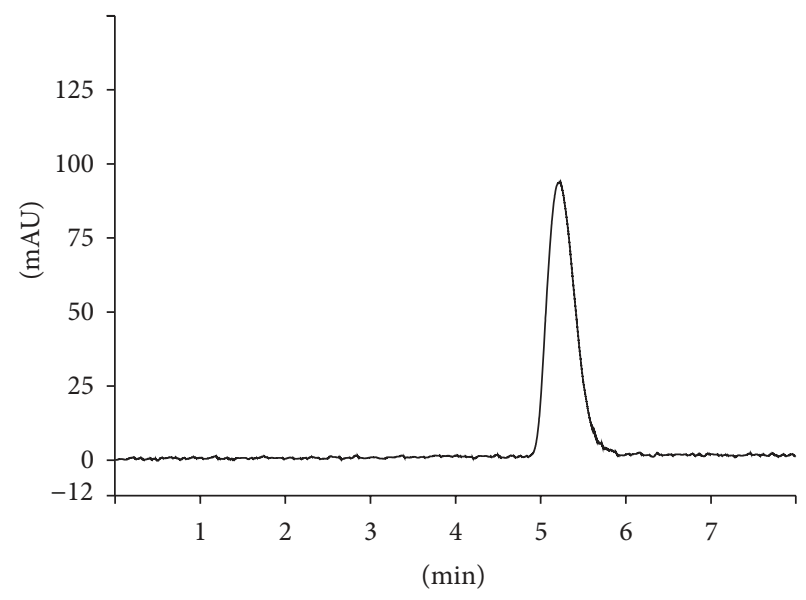

(d)

FiguRE 3: HPLC chromatograms $(\lambda=320 \mathrm{~nm}$ ) obtained from unloaded and FA-loaded microparticles: M1FA0 (a), M1FA10 (b), M2FA0 (c), and M2FA10 (d).

specificity, linearity, limit of detection, limit of quantification, accuracy, precision, and robustness [21].

3.2.1. Specificity. Specificity was demonstrated by comparing the chromatograms of unloaded and FA-loaded microparticles prepared as per test method. The results showed that there was no interference at the retention time of FA from the other formulation components. In that sense, it is possible to confirm the specificity of the purposed method (Figure 3). Moreover, the photodiode array detector indicated that FA peak was free from interference (purity index $>0.9999$ ).

3.2.2. Linearity. A linear relationship between peak area and concentration of FA at the concentration range of 10.0 to $70.0 \mu \mathrm{g} / \mathrm{mL}$ was observed (Figure 4). The linear equation obtained by the least-square method was $y=51.1011 x+$ 26.2381, where $y$ is the peak area and $x$ is the standard solution concentration in $\mu \mathrm{g} / \mathrm{mL}$. A suitable correlation coefficient ( $r=0.9998$ ) was recorded which demonstrates that the method is remarkable linear with an $r$ value of nearly 1 at the purposed range.
3.2.3. Limit of Detection (LOD) and Limit of Quantification (LOQ). The lowest concentration where FA can be detected (LOD) and quantified (LOQ) with acceptable precision and accuracy was 0.334 and $1.012 \mu \mathrm{g} / \mathrm{mL}$, respectively. These results represent that the chromatographic method is suitable enough to detect and quantify FA at the concentration range of 10.0 to $70.0 \mu \mathrm{g} / \mathrm{mL}$.

3.2.4. Accuracy. The accuracy was evaluated using a recovery study and showed mean recoveries for the three levels of concentration ranging between 99 and 101\% (Table 3). These recovery values indicate that the developed method was accurate for the determination of FA in polymeric microparticles.

3.2.5. Precision. Precision was verified by repeatability and intermediate precision as presented in Table 4 . The relative standard deviation (RSD) values were less than $1.43 \%$ and $1.93 \%$ for intra- and interday precision, respectively. These results confirm the good precision of the chromatographic method. 
TABLE 3: Accuracy assays for ferulic acid analysis*.

\begin{tabular}{lccc}
\hline Level of concentration & $\begin{array}{c}\text { Theoretical concentration } \\
(\mu \mathrm{g} / \mathrm{mL})\end{array}$ & $\begin{array}{c}\text { Experimental concentration } \\
(\mu \mathrm{g} / \mathrm{mL})\end{array}$ & Recovery $(\%)$ \\
\hline Low & 15 & $15.11 \pm 0.25$ & 100.73 \\
Medium & 45 & $44.91 \pm 0.44$ & 99.80 \\
High & 65 & $64.36 \pm 0.55$ & 99.02 \\
\hline${ }^{* * *}$ & & & 0.98 \\
\hline
\end{tabular}

${ }^{*} n=3 ;{ }^{*} \mathrm{RSD}=$ relative standard deviation.

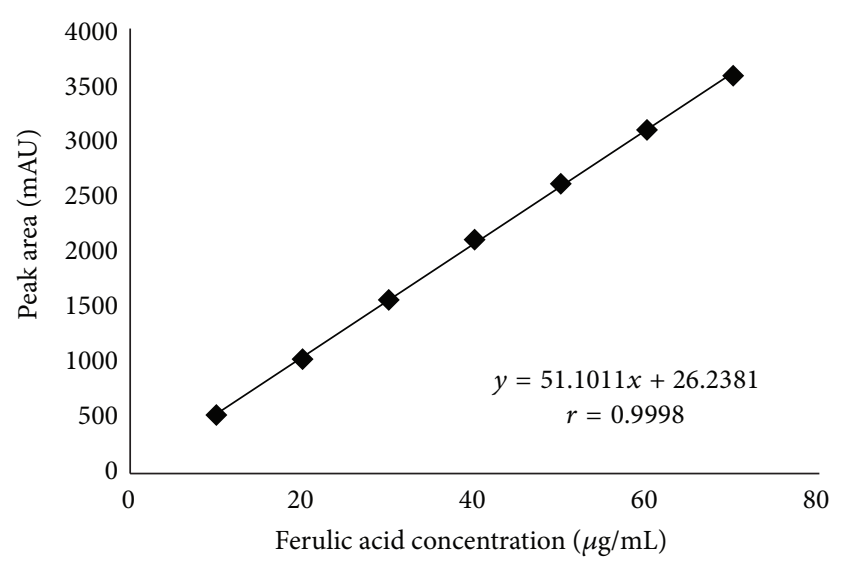

FIGURE 4: Mean calibration curve obtained for FA using working standard solutions at the concentration range of 10.0 to $70.0 \mu \mathrm{g} / \mathrm{mL}$ $(n=3)$.

TABLE 4: Repeatability and intermediate precision data for ferulic acid analysis.

\begin{tabular}{lcc}
\hline $\begin{array}{l}\text { Sample solution } \\
(\mu \mathrm{g} / \mathrm{mL})\end{array}$ & $\begin{array}{c}\text { Measured concentration } \pm \mathrm{SD}^{*} \\
(\mu \mathrm{g} / \mathrm{mL})\end{array}$ & $\mathrm{RSD}^{* *}(\%)$ \\
\hline $\begin{array}{l}\text { Repeatability } \\
(n=9)\end{array}$ & & \\
15 & $16.82 \pm 0.24$ & 1.43 \\
40 & $40.21 \pm 0.31$ & 0.77 \\
65 & $64.67 \pm 0.30$ & 0.46 \\
Intermediate & & \\
precision $(n=3)$ & & \\
$\quad$ Day 2 & & 0.13 \\
$\quad 40$ & $39.44 \pm 0.05$ & \\
$\quad$ Day 3 & & 1.93 \\
$\quad 40$ & $40.32 \pm 0.78$ & \\
\hline
\end{tabular}

${ }^{*} \mathrm{SD}=$ standard deviation; ${ }^{* *} \mathrm{RSD}=$ relative standard deviation.

3.2.6. Robustness. The evaluation of robustness was based on RSD values obtained by changing analytical parameters such as temperature of analytical column $\left(30\right.$ and $\left.40^{\circ} \mathrm{C}\right)$, isocratic flow rate $(0.9$ and $1.1 \mathrm{~mL} / \mathrm{min})$, and $\mathrm{pH}$ of mobile phase (4.0 and 6.0). Concerning these parameters, the method was considered robust because RSD for the drug content analyses values were lower than $2.24 \%$ as summarized in Table 5 . Therefore, changes in these chromatographic parameters did not affect the analysis of FA into polymeric microparticles. As
TABLE 5: Robustness data for ferulic acid analysis $(n=3)$.

\begin{tabular}{lccc}
\hline Parameter & $\begin{array}{c}\text { Drug content } \\
(\%) \pm \text { SD }^{*}\end{array}$ & RSD $^{* *}$ & $\begin{array}{c}\text { Retention } \\
\text { time }(\mathrm{min})\end{array}$ \\
\hline $\begin{array}{l}\text { Flow rate } \\
(\mathrm{mL} / \mathrm{min})\end{array}$ & & & \\
0.9 & $102.71 \pm 1.93$ & 1.88 & 5.39 \\
1.0 & $100.12 \pm 0.60$ & 0.60 & 4.86 \\
1.1 & $99.78 \pm 0.57$ & 0.57 & 4.49 \\
$\mathrm{pH}$ of mobile & & & \\
phase & & & \\
3.0 & $100.12 \pm 0.60$ & 0.60 & 4.86 \\
4.0 & $97.56 \pm 0.98$ & 1.00 & 4.80 \\
$\quad 6.0$ & $98.03 \pm 0.37$ & 0.38 & 4.52 \\
Temperature & & & \\
$\left({ }^{\circ} \mathrm{C}\right)$ & & & \\
$\quad$ Ambient & $100.12 \pm 0.60$ & 0.60 & 4.86 \\
30 & $100.09 \pm 1.09$ & 1.09 & 4.71 \\
$\quad 40$ & $99.14 \pm 2.22$ & 2.24 & 4.44 \\
\hline${ }^{*} \mathrm{SD}=$ standard deviation: ${ }^{* *} \mathrm{RSD}=$ relative standard deviation.
\end{tabular}

expected, some variation in the retention time was observed without compromising the determination of drug content.

3.3. Forced Degradation Study. Regarding the presence of degradation products, forced degradation study showed different results depending on the stress condition used. After exposure to acid medium, approximately $29.37 \%$ of FA was degraded (Figure 5(a)) and the drug peak was recorded at 4.56 min. In alkaline condition, a FA degradation of $16.33 \%$ was observed and the drug peak was detected at $4.55 \mathrm{~min}$ (Figure 5(b)). No previous report was devoted to investigate the drug degradation using $0.1 \mathrm{M} \mathrm{HCl}$ and $0.1 \mathrm{M} \mathrm{NaOH}$. Under photolytic conditions, decreases in FA concentration from methanol solution were observed (Figure 6). On the other side, the cuvette covered by aluminum paper showed no degradation after $6 \mathrm{~h}$ which indicates that no thermal degradation was involved in the photodegradation process. Moreover, no additional peak was verified in the chromatograms of the forced degradation study demonstrating that the degradation products were not detected using the optimized chromatographic conditions.

Aiming at elucidating the kinetics of FA photodegradation from methanol solution, the experimental data were fitted to zero, first, and second order equations. These plots (Figure 6) indicated that FA photodegradation process in methanol solution followed a second order kinetic with a rate 


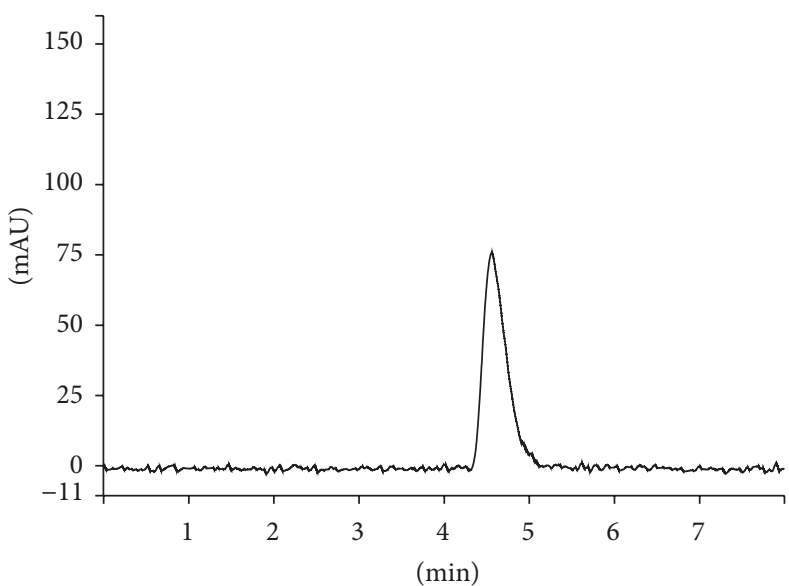

(a)

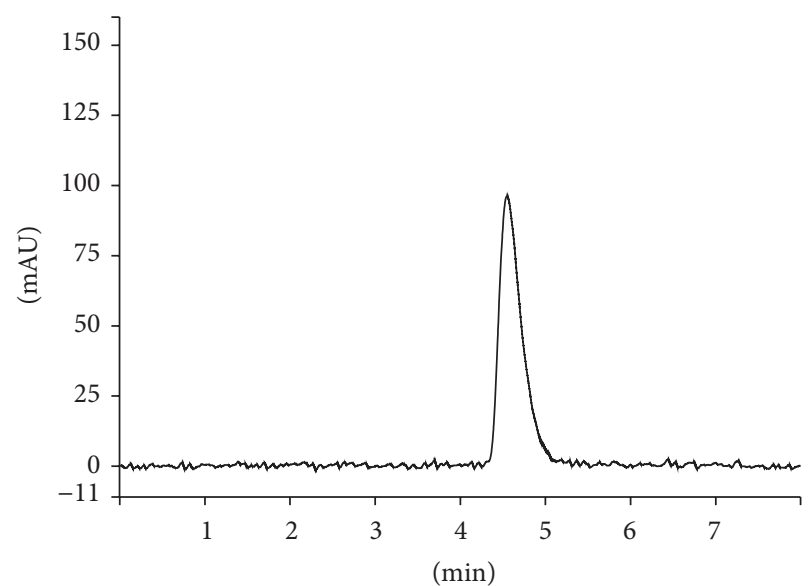

(b)

FIGURE 5: Chromatograms obtained after one hour of FA exposure under acid (a) and alkaline (b) conditions.

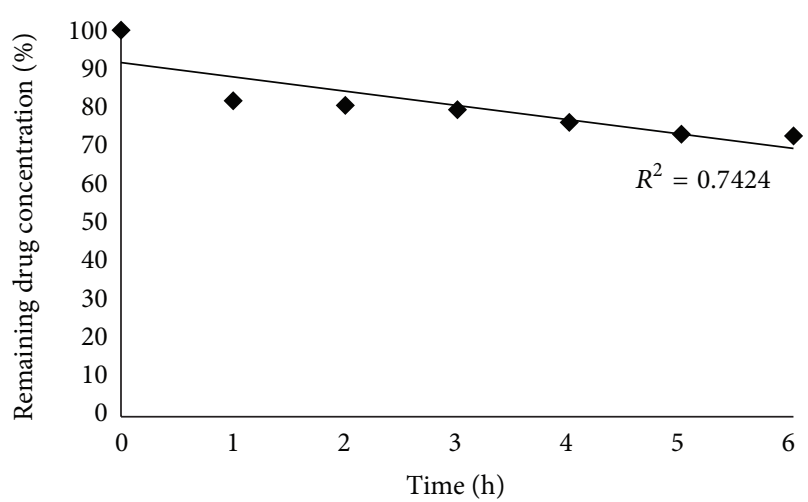

(a)

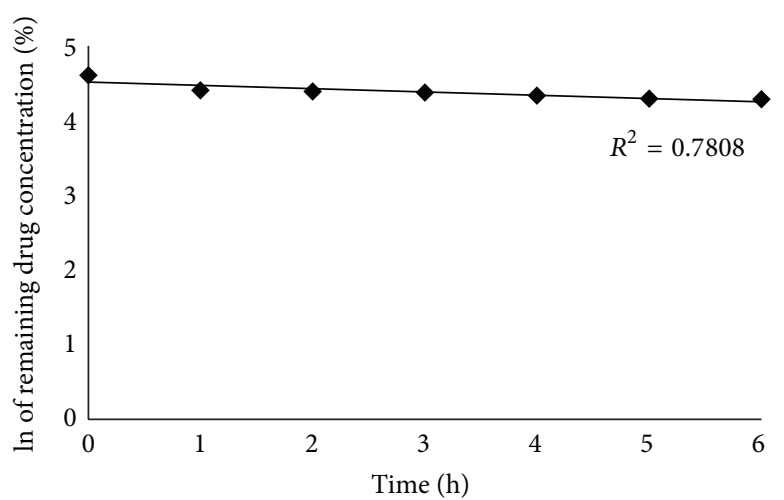

(b)

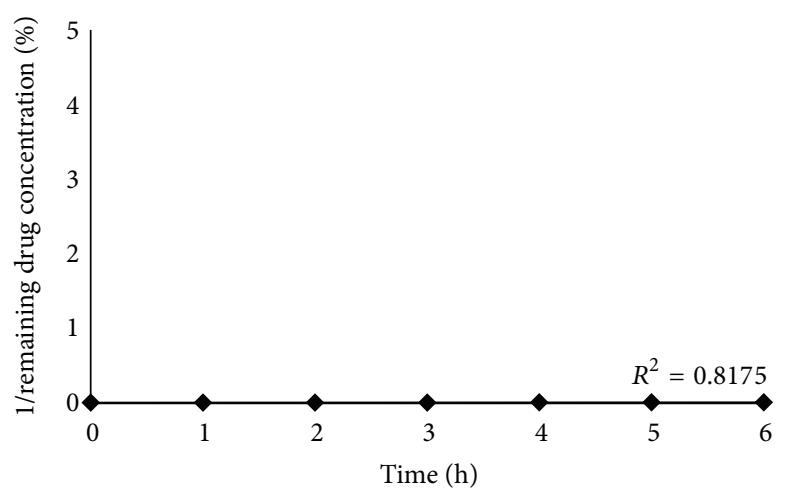

(c)

FIgURE 6: Plots of remaining FA concentration versus time for zero order (a), first order (b), and second order (c) equations.

constant of $6.27 \times 10^{4} \mathrm{~L} / \mathrm{mol} \times \mathrm{h}$. In this case, the degradation of FA is dependent on the drug concentration.

3.4. Evaluation of Encapsulation Efficiency. The drug content and encapsulation efficiency (EE) of FA into PHBV/PCL microparticles was carried out by the previously validated HPLC-DAD method and the obtained results are represented in Table 6. High percentages of drug entrapment were obtained for PHBV/PCL microparticles by simple emulsion/solvent evaporation. All formulations showed suitable EE values higher than $98 \%$.

These values are mainly based on the poor aqueous solubility $(6.63 \mathrm{mg} / \mathrm{dL}$ at $\mathrm{pH}=7.2)$ of FA [4] which leads to increase the drug loaded into polymeric microparticles. The current results are similar or better than previously reported. Stearic acid- and stearyl ferulate-based solid lipid 
TABLE 6: Ferulic acid-loaded ${ }^{*}$ and encapsulation efficiency (EE) for PHBV/PCL microparticles.

\begin{tabular}{lcc}
\hline Microparticles & Ferulic acid-loaded $\left({\left.\mathrm{mg} \cdot \mathrm{g}^{-1}\right)}\right.$ & EE $(\%)$ \\
\hline M1FA5 & $49.51 \pm 0.21$ & 99.02 \\
M1FA10 & $100.12 \pm 0.60$ & 100.12 \\
M1FA20 & $198.65 \pm 0.97$ & 99.32 \\
M2FA5 & $49.35 \pm 1.76$ & 98.70 \\
M2FA10 & $98.70 \pm 2.06$ & 98.70 \\
M2FA20 & $198.20 \pm 2.45$ & 99.10 \\
\hline
\end{tabular}

${ }^{*}$ Mean $(n=3) \pm$ standard deviation.

nanoparticles containing trans-FA revealed a drug entrapment of 95.4 and 97.7\%, respectively [12]. Poly(lactic-coglycolic acid) nanoparticles containing FA showed EE of about $76 \%$ [7]. A FA entrapment higher than $60 \%$ was achieved for inclusion complex of trans-FA and hydroxypropyl- $\beta$-cyclodextrin that was prepared by the freeze-drying method [2].

Therefore, the validated method was successfully applied to the determination of FA into polymeric microparticles and can be considered an important tool for the quality control of these promising formulations.

\section{Conclusion}

A simple and efficient reverse-phase HPLC-DAD method was developed and validated for quantitative determination of FA into polymeric microparticles. In summary, the method was found to be specific, linear, accurate, precise, and robust for a rapid determination of this drug and can be used for studying the stability and degradation kinetics of FA.

\section{Conflict of Interests}

The authors confirm that this paper's content has no conflict of interests.

\section{Acknowledgment}

The authors are thankful to CAPES, Brazil, and Araucaria Foundation, Brazil, for financial support.

\section{References}

[1] C. Mancuso and R. Santangelo, "Ferulic acid: pharmacological and toxicological aspects," Food and Chemical Toxicology, vol. 65, pp. 185-195, 2014.

[2] J. Wang, Y. Cao, B. Sun, and C. Wang, "Characterisation of inclusion complex of trans-ferulic acid and hydroxypropyl- $\beta$ cyclodextrin," Food Chemistry, vol. 124, no. 3, pp. 1069-1075, 2011.

[3] S. Itagaki, T. Kurokawa, C. Nakata et al., "In vitro and in vivo antioxidant properties of ferulic acid: a comparative study with other natural oxidation inhibitors," Food Chemistry, vol. 114, no. 2, pp. 466-471, 2009.

[4] A. Saija, A. Tomaino, D. Trombetta et al., "In vitro and in vivo evaluation of caffeic and ferulic acids as topical photoprotective agents," International Journal of Pharmaceutics, vol. 199, no. 1, pp. 39-47, 2000.

[5] Z. Zhao and M. H. Moghadasian, "Chemistry, natural sources, dietary intake and pharmacokinetic properties of ferulic acid: a review," Food Chemistry, vol. 109, no. 4, pp. 691-702, 2008.

[6] F. M. F. Roleira, C. Siquet, E. Orrù et al., "Lipophilic phenolic antioxidants: correlation between antioxidant profile, partition coefficients and redox properties," Bioorganic and Medicinal Chemistry, vol. 18, no. 16, pp. 5816-5825, 2010.

[7] J. J. P. Merlin, N. R. Prasad, S. M. A. Shibli, and M. Sebeela, "Ferulic acid loaded Poly- $d, l$-lactide-co-glycolide nanoparticles: systematic study of particle size, drug encapsulation efficiency and anticancer effect in non-small cell lung carcinoma cell line in vitro," Biomedicine and Preventive Nutrition, vol. 2, no. 1, pp. 69-76, 2012.

[8] V. Staniforth, W.-C. Huang, K. Aravindaram, and N.-S. Yang, "Ferulic acid, a phenolic phytochemical, inhibits UVB-induced matrix metalloproteinases in mouse skin via posttranslational mechanisms," Journal of Nutritional Biochemistry, vol. 23, no. 5, pp. 443-451, 2012.

[9] N. Du, S. Cao, and Y. Yu, "Research on the adsorption property of supported ionic liquids for ferulic acid, caffeic acid and salicylic acid," Journal of Chromatography B: Analytical Technologies in the Biomedical and Life Sciences, vol. 879, no. 19, pp. 16971703, 2011.

[10] D.-G. Yu, J.-M. Yang, C. Branford-White, P. Lu, L. Zhang, and L.-M. Zhu, "Third generation solid dispersions of ferulic acid in electrospun composite nanofibers," International Journal of Pharmaceutics, vol. 400, no. 1-2, pp. 158-164, 2010.

[11] S. Scalia and M. Mezzena, "Incorporation of quercetin in lipid microparticles: effect on photo- and chemical-stability," Journal of Pharmaceutical and Biomedical Analysis, vol. 49, no. 1, pp. 9094, 2009.

[12] S. Trombino, R. Cassano, T. Ferrarelli, E. Barone, N. Picci, and C. Mancuso, "Trans-ferulic acid-based solid lipid nanoparticles and their antioxidant effect in rat brain microsomes," Colloids and Surfaces B, vol. 109, pp. 273-279, 2013.

[13] D. T. Birnbaum and L. Brannon-Peppas, "Microparticle drug delivery systems," in Drug Delivery Systems in Cancer Therapy, D. M. Brown, Ed., pp. 117-135, Humana Press, Totowa, NJ, USA, 1st edition, 2003.

[14] S. M. G. Reinke, M. C. S. Rastelli, R. Garcia et al., "Chlorhexidine digluconate-loaded (Meth)acrylic microparticles: high encapsulation efficiency and prolonged release," Latin American Journal of Pharmacy, vol. 33, no. 1, pp. 47-55, 2014.

[15] V.-T. Tran, J.-P. Benoît, and M.-C. Venier-Julienne, "Why and how to prepare biodegradable, monodispersed, polymeric microparticles in the field of pharmacy?" International Journal of Pharmaceutics, vol. 407, no. 1-2, pp. 1-11, 2011.

[16] S.-M. Ng, J.-Y. Choi, H.-S. Han, J.-S. Huh, and J. O. Lim, "Novel microencapsulation of potential drugs with low molecular weight and high hydrophilicity: hydrogen peroxide as a candidate compound," International Journal of Pharmaceutics, vol. 384, no. 1-2, pp. 120-127, 2010.

[17] M. Li, O. Rouaud, and D. Poncelet, "Microencapsulation by solvent evaporation: state of the art for process engineering approaches," International Journal of Pharmaceutics, vol. 363, no. 1-2, pp. 26-39, 2008.

[18] C. Anselmi, M. Centini, M. Ricci et al., "Analytical characterization of a ferulic acid/gama-cyclodextrin inclusion complex," Journal of Pharmaceutical and Biomedical Analysis, vol. 40, no. 4, pp. 875-881, 2006. 
[19] ICH Q1A (R2), Stability Testing of New Drug Substances and Products, 2003.

[20] ICH, Q1B Photostability Testing on New Drug Substances and Products, ICH, 1996.

[21] ICH, Q2(R1) Validation of Analytical Procedures: Text and Methodology, ICH, 2005.

[22] M. K. Riekes, F. M. Barboza, D. D. Vecchia et al., "Evaluation of oral carvedilol microparticles prepared by simple emulsion technique using poly(3-hydroxybutyrate-co-3-hydroxyvalerate) and polycaprolactone as polymers," Materials Science and Engineering C, vol. 31, no. 5, pp. 962-968, 2011.

[23] Y. $\mathrm{Li}$ and $\mathrm{K}$. Bi, "HPLC determination of ferulic acid in rat plasma after oral administration of Rhizoma Chuanxiong and its compound preparation," Biomedical Chromatography, vol. 17, no. 8, pp. 543-546, 2003.

[24] X. Li, X. Li, L. Wang, Y. Li, Y. Xu, and M. Xue, "Simultaneous determination of danshensu, ferulic acid, cryptotanshinone and tanshinone IIA in rabbit plasma by HPLC and their pharmacokinetic application in danxiongfang," Journal of Pharmaceutical and Biomedical Analysis, vol. 44, no. 5, pp. 1106-1112, 2007.

[25] I.-J. Lin, T.-M. Cham, and S.-M. Wu, "Simultaneous determination of hesperidin, ferulic acid, cinnamic acid and cinnamaldehyde in chinese tonic wine by high performance liquid chromatography," Journal of the Chinese Chemical Society, vol. 57, no. 3, pp. 429-435, 2010.

[26] Y. Chen, Y. Li, X. Chen et al., "Development and validation of a HPLC method for the determination of five bioactive compounds in the 'xuebijing' injection," Analytical Letters, vol. 43, no. 15, pp. 2456-2464, 2010.

[27] J. Vichapong, M. Sookserm, V. Srijesdaruk, P. Swatsitang, and S. Srijaranai, "High performance liquid chromatographic analysis of phenolic compounds and their antioxidant activities in rice varieties," LWT-Food Science and Technology, vol. 43, no. 9, pp. 1325-1330, 2010.

[28] J. B. Weon, J. Y. Ma, H. J. Yang, and C. J. Ma, "Simultaneous determination of ferulic acid, hesperidin, 6-gingerol and glycyrrhizin in Insampaedok-san by HPLC coupled with diode array detection," Journal of Analytical Chemistry, vol. 67, no. 12, pp. 955-959, 2012.

[29] Z. Ouyang, M. Zhao, J. Tang, and L. Pan, "In vivo pharmacokinetic comparisons of ferulic acid and puerarin after oral administration of monomer, medicinal substance aqueous extract and Nao-De-Sheng to rats," Pharmacognosy Magazine, vol. 8, no. 32, pp. 256-262, 2012.

[30] J. Kareparamban, P. Nikam, A. Jadhav, and V. Kadam, "A validated high-performance liquid chromatograhy method for estimation of ferulic acid in asafoetida and polyherbal preparation," Indian Journal of Pharmaceutical Sciences, vol. 75, no. 4, pp. 493-495, 2013. 

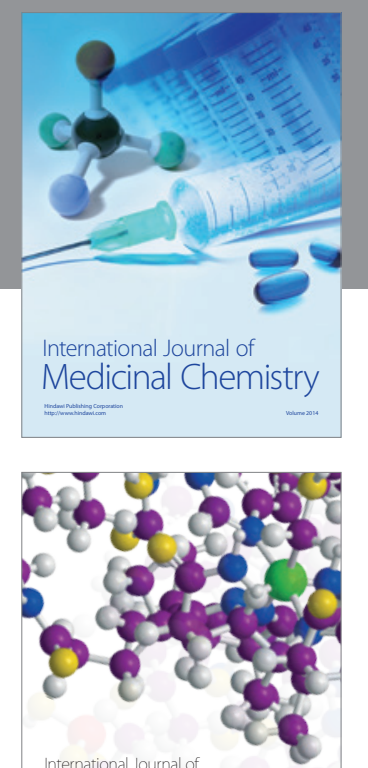

\section{Carbohydrate} Chemistry

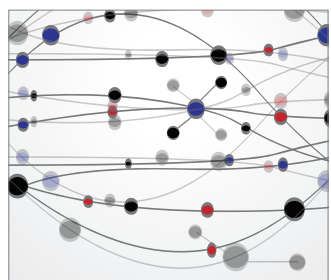

The Scientific World Journal
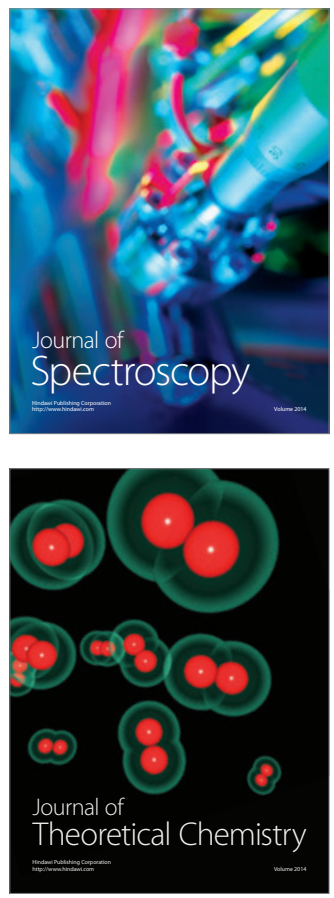
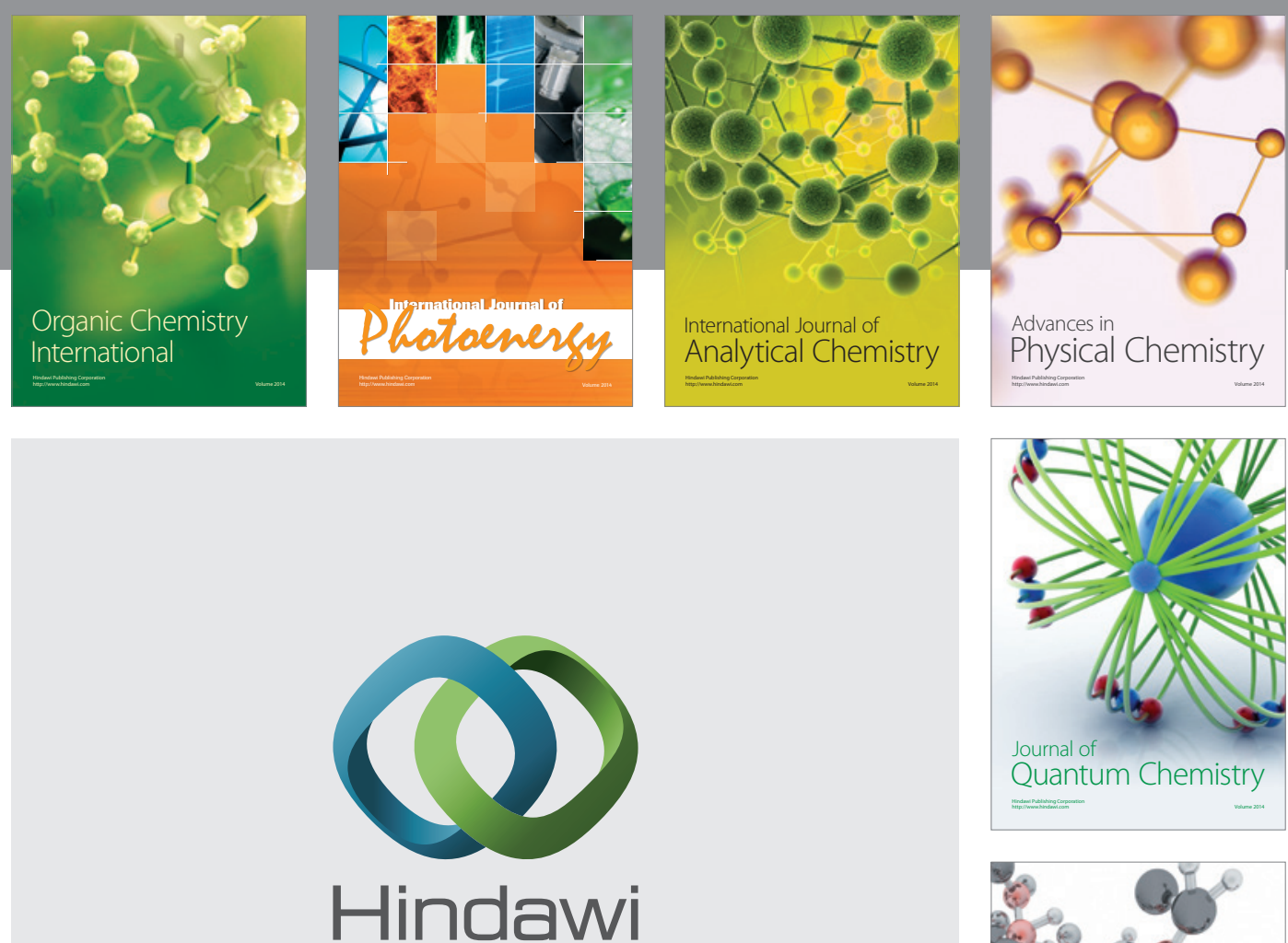

Submit your manuscripts at

http://www.hindawi.com

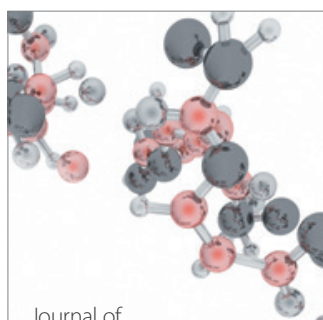

Analytical Methods

in Chemistry

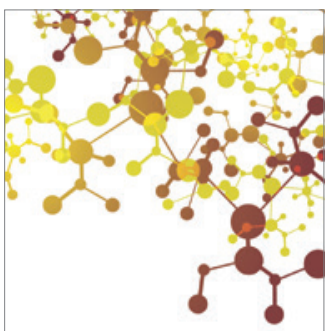

Journal of

Applied Chemistry

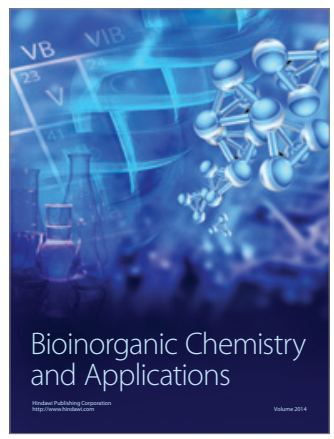

Inorganic Chemistry
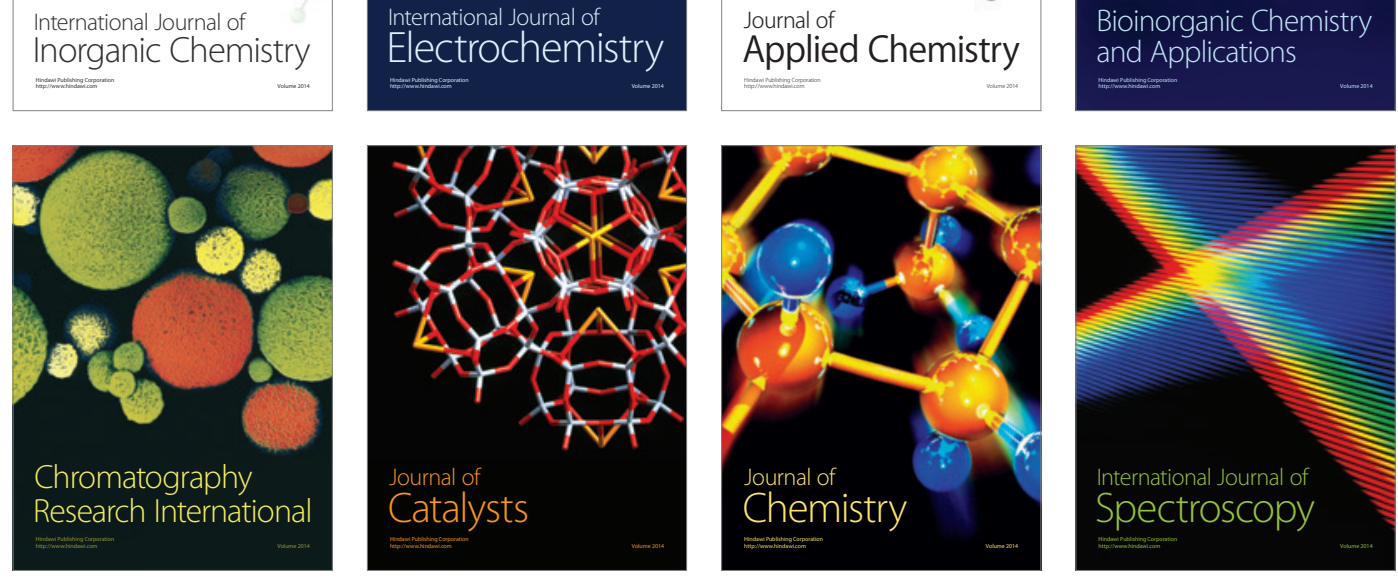